\title{
A PREDICTION RULE FOR DURATION OF DISABILITY BENEFITS IN WORKERS WITH NONSPECIFIC LOW BACK
} PAIN

Ivan Steenstra, Sheilah Hogg-Johnson, Arold Davilmar, Hyunmi Lee, Renee-Louise Franche, David Toluso, Andrea Furlan, Jason Busse, Ben Amick III Institute for Work \& Health, Toronto, Canada

10.1136/oemed-2011-100382.243

Objectives This study examines factors collected within the first 4 weeks of work disability to predict outcomes for workers on benefits due to back pain at $6 \& 24$ months.

Methods Routinely collected information from the compensation agency on: age, gender, occupation, earnings, nature and event of injury, language, job tenure, history of prior claims, physical work, healthcare and opioid use will be analysed. Additional data was extracted via claim file review: need for a translator, previous claims in other jurisdictions, workplace offer of modified work, and work limitations suggested by health professional. Data from the Readiness for Return to Work cohort study on health, functional status pain, mental health, expectations for recovery, job satisfaction, and supervisor's response are available for a subset of workers. Benefits status at 6 months will be studied using logistic regression. Cox regression and mover stayer models will be used for time on disability benefits and recurrences during the 2 years of follow-up.

Results 6657 workers were selected and additional information was entered in the research database. 1796 were still on full benefits at 4 weeks. $38 \%$ were female, $81 \%$ of workplace reported to offer workplace accommodation, $48 \%$ of workers were represented by a union, 5056 prescriptions for oxycodone were reimbursed in the first 4 weeks. 300 workers were still off work 6 months after date of injury.

Conclusions A prediction tool that provides projections of different injured worker outcomes such as time remaining on benefits and likelihood of a recurrence will be presented. 